\title{
Water Sorption/Desorption Kinetics and Convective Drying of Eucalyptus globulus Wood $^{1}$
}

\author{
Mahyoub AMER(D ${ }^{2, \dagger} \cdot$ Bousselham KABOUCHI ${ }^{2} \cdot$ Salah El ALAMI ${ }^{2} \cdot$ Brahim AZIZE $^{2}$ • \\ Mohamed RAHOUTI ${ }^{3} \cdot$ Abderrahim FAMIRI $^{4} \cdot$ Abdelwahed FIDAH $^{4}$
}

\begin{abstract}
Radial and tangential water diffusion in Eucalyptus globulus wood was investigated using three mature trees from a forest in Khemis Sahel (North Morocco). Absorption and desorption kinetics experiments were conducted at ambient temperature $\left(25{ }^{\circ} \mathrm{C}\right)$ and $30{ }^{\circ} \mathrm{C}$, respectively, and a relative humidity of $60 \%$. The diffusion coefficients in the two directions were determined under imposed hygrothermal conditions; they were greater in the radial direction for the absorption as well as desorption processes. Convective drying under load, preceded by reconditioning and followed up by balancing, revealed the drying conditions that corresponded to the appropriate drying schedules for E. globulus wood. This was verified by measuring the cracks and bowsbefore and after drying of boards.
\end{abstract}

Keywords: wood, Eucalyptus globulus, absorption kinetic, desorption kinetic, diffusion coefficient, convective drying

\section{INTRODUCTION}

Eucalyptus trees have a major socio-economic role in Morocco, due to their plasticity and rapid growth capacity (Famiri et al., 2001). Indeed, Eucalyptus wood is used in the industry as pulp, logs, firewood and charcoal. However, the uses of eucalyptus as a timber remain limited because the appearance of cracks and/or splits due to the growth stresses releasing during cutting, sawing and drying. In addition, the eucalyptus exhibit high shrinkage and collapses (Maziri et al., 2010;
Wessels et al., 2016; Amer et al., 2017).

Beneficial use of eucalyptus such Eucalyptus globulus wood needs searching methods to reduce these defects. This requires a study of water transfer in this kind of wood and control the drying rate. Diffusivity of water is an important phenomenon in wood drying studies (Peralta and Bangi, 2003; Kouchade, 2004; Ghazil, 2010).

Wood is a hygroscopic material. In storage, it is exposed to both absorption and desorption processes of moisture from the surrounding air (Baronas et al.,

${ }^{1}$ Date Received April 5, 2019, Date Accepted August 10, 2019

${ }^{2}$ Laboratory of Condensed Matter and Interdisciplinary Sciences, Faculty of Sciences, Mohammed V University in Rabat, 4 Avenue Ibn Battouta B.P. 1014 RP, Morocco

${ }^{3}$ Center of Plant and Microbial Biotechnologies, Biodiversity and Environment, Faculty of Sciences, Mohammed V University in Rabat, 4 Avenue Ibn Battouta B.P. 1014 RP, Morocco

${ }^{4}$ Physics Mechanics of Wood Laboratory, Research Centre of Forestry in Rabat, Charia Omar Ibn Al Khattab. B.P, 763 Agdal-Rabat 10050 Morocco

† Corresponding author: Mahyoub AMER (e-mail: mahyoub51973@gmail.com, ORCID: 0000-0003-0547-8970) 
Mahyoub AMER • Bousselham KABOUCHI - Salah El ALAMI • Brahim AZIZE • Mohamed RAHOUTI Abderrahim FAMIRI $\cdot$ Abdelwahed FIDAH

2001; Okoh, 2014). Moisture content significantly influences wood physical and mechanical properties, which are of great importance for wood uses in different applications areas (Shi, 2007; Noorolahi et al., 2008; Sonderegger et al., 2011; Franke et al., 2016; Lee and Lee, 2018; Pang and Jeong, 2019).

Water transfer in wood is a very complex process. It diffuses in three different forms: free water in wood above fiber saturation point (FSP), bound water and water vapor in the wood below FSP point (Vasic et al., 2012; Engelund et al., 2013; Okoh, 2014; Bennani et al., 2017). Water diffusion in wood depends on numerous factors, such as wood moisture content, diffusion direction, time, temperature, relative humidity and type of wood (Jannot et al., 2006; Tamme et al., 2011; Sandoval-Torres et al., 2014; Kim et al., 2017).

Drying eucalyptus wood can be done naturally or industrially, but conventional kiln drying is the most common practice among the artificial drying methods used in the wood industry (Travan et al., 2010; Chang et al., 2017; Kang and Kang, 2018). The conventional kilns typically operate in temperatures ranging from 40 to $80{ }^{\circ} \mathrm{C}$ (Batista et al., 2013).

In this work, we studied the water diffusion in $E$. globulus wood in radial and tangential directions at a fixed temperature and relative humidity values by analyzing absorption and desorption kinetics of water and estimating the diffusion coefficients. We also investigated convective drying tests in order to reduce defects and get a good quality of drying for the considered wood.

\section{MATERIALS and METHODS}

\subsection{Materials}

The vegetal material used in this study consists of three trees of E. globulus Labill. from the Khmiss Sahel forest in Larache region (North of Morocco). The
Table 1. Dendrometric measurements of the studied trees

\begin{tabular}{ccccc}
\hline Tree & $\mathrm{h}_{\mathrm{t}}(\mathrm{m})$ & $\mathrm{C}_{1.3}(\mathrm{~m})$ & $\mathrm{C}_{\text {base }}(\mathrm{m})$ & $\mathrm{MC}(\%)$ \\
\hline 1 & 15 & 1.18 & 1.90 & 91 \\
2 & 14 & 1.03 & 1.82 & 89 \\
3 & 13 & 1.00 & 1.80 & 89 \\
\hline
\end{tabular}

where $h_{t}$ : total tree height, $C_{1.3}$ : circumference at $1.3 \mathrm{~m}$, $\mathrm{C}_{\text {base: }}$ circumference at the base, and MC: moisture content.

selected trees are more than 30-years-old. The corresponding circumferences are ranged between 100 and $118 \mathrm{~cm}$. These trees have a good straightness and are free of defects. In Table 1, we reported dendrometric characteristics measurements of sampled trees.

\subsection{Preparation of test specimens}

The wood samples used in this study were taken from the heartwood along the same longitudinal bars and the first log of each tree. The selected samples have a parallelepipedic form with dimensions $(20 \times$ $20 \times 15) \mathrm{mm}^{3}$ (Fig. 1). We have prepared 40 specimens for studying absorption kinetics in the radial direction (20 samples) and tangential direction (20 samples). The same number (40 specimens) is used in the desorption study. The samples were covered with aluminum tape on the four sides. The water diffusion in radial or tangential directions is studied along the two other open sides.

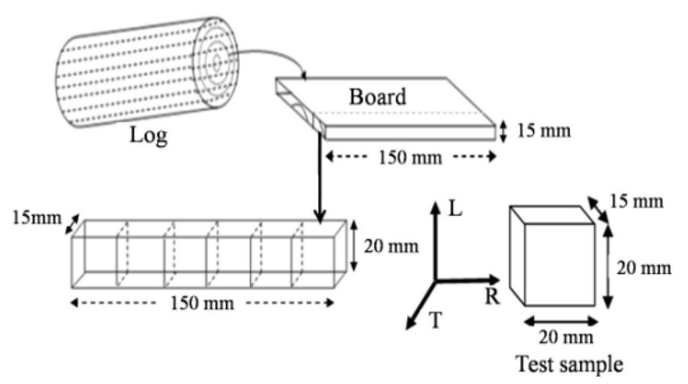

Fig. 1. Test specimen preparation for sorption and desorption kinetic studies. 


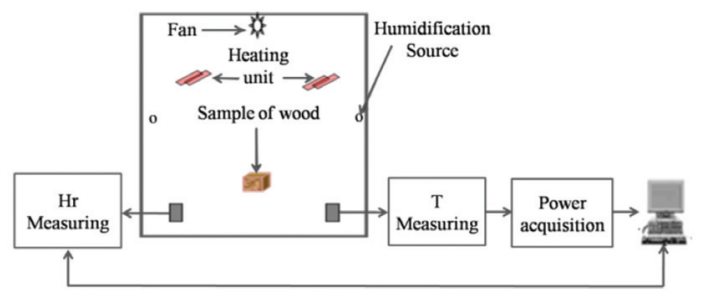

Fig. 2. Experimental material used in desorption experiments.

\subsection{Experimental}

Water diffusion in E. globulus wood was carried out by using a water basin for absorption study and a climatically chamber for desorption measurement (Fig. 2). The climatic conditions (temperature $T$ and relative humidity $\mathrm{Hr}$ ) surrounding the samples were controlled during desorption experiments.

\subsection{Measurement method}

To follow water absorption kinetics in the wood, the samples which have initially moisture content about $10 \%$ were submerged in the water basin at ambient temperature $\left(25^{\circ} \mathrm{C}\right)$. The changes in the samples weight are recorded at regular intervals time (each 2 min) until saturation in 24 hours.

In the study of desorption kinetic, the moisture content in the wood samples was almost $60 \%$ initially. The samples were placed in climatically chamber at temperature $30{ }^{\circ} \mathrm{C}$ and relative humidity $60 \%$, their weights were measured at regular time intervals during 24 hours until equilibrium state.

The relative humidity and samples weights were measured respectively by a digital hygrometer of accuracy $(0.01 \%)$ and an electronic balance with precision $(0.001 \mathrm{~g})$ controlled with a computer.

The wood samples were placed in an oven at $103{ }^{\circ} \mathrm{C}$ during 48 hours to obtain the dry mass and to determine the moisture content.

\subsection{Mathematical formulations}

The wood moisture content denoted (MC) is equal to the quantity of water contained in the wood, expressed as a percentage of dry weight:

$$
\mathrm{MC}(\%)=\frac{\mathrm{W}_{\mathrm{h}}-\mathrm{W}_{\mathrm{o}}}{\mathrm{W}_{\mathrm{o}}} \times 100
$$

where $\mathrm{W}_{\mathrm{h}}$ : wet wood mass $(\mathrm{g})$, and $\mathrm{W}_{\mathrm{o}}$ : dry wood mass (g).

Driving force of transfer is moisture gradient. The following approach treats the internal transfer mechanism of moisture diffusion in wood. According to Fick's second law, the diffusion equation is given by (Houngan et al., 2015):

$$
\frac{\partial C}{\partial t}=\frac{d}{d x}\left(D \frac{d C}{d x}\right)
$$

where $C=C(\mathrm{x}, \mathrm{t})$ : wood moisture concentration ( $\mathrm{g}$ $\mathrm{cm}^{-3}$ ) at the $\mathrm{x}$ thickness $(\mathrm{cm})$ in time $\mathrm{t}(\mathrm{s})$, and $\mathrm{D}$ : the diffusion coefficient $\left(\mathrm{m}^{2} \mathrm{~s}^{-1}\right)$. By defining a dimensionless water content $\mathrm{C}^{+}$:

$$
\mathrm{C}^{+}=\frac{\mathrm{C}-\mathrm{C}_{\mathrm{eq}}}{\mathrm{C}_{\mathrm{in}}-\mathrm{C}_{\mathrm{eq}}} \cong \frac{\mathrm{MC}-\mathrm{MC}_{\mathrm{eq}}}{\mathrm{MC}_{\mathrm{in}}-\mathrm{MC}_{\mathrm{eq}}}
$$

where $\mathrm{C}_{\mathrm{eq}}$ and $\mathrm{MC}_{\mathrm{eq}}$ : average samples moisture concentration $\left(\mathrm{g} \mathrm{cm}^{-3}\right)$ and moisture content (\%) at equilibrium according to the hygro-thermal imposed conditions, $\mathrm{C}_{\text {in }}$ and $\mathrm{MC}_{\text {in }}$ : average initial moisture concentration $\left(\mathrm{g} \mathrm{cm}^{-3}\right)$ and moisture content (\%) in the samples, $\mathrm{C}$ and MC: average moisture concentration $\left(\mathrm{g} \mathrm{cm}^{-3}\right)$ and moisture content (\%) in wood samples at the time $\mathrm{t}(\mathrm{s})$.

Assuming that $\mathrm{D}$ is constant, equation (2) becomes:

$$
\frac{\partial \mathrm{C}^{+}}{\partial \mathrm{t}}=\mathrm{D} \frac{\mathrm{d}^{2} \mathrm{C}^{+}}{\mathrm{dx}^{2}}
$$


Mahyoub AMER • Bousselham KABOUCHI - Salah El ALAMI - Brahim AZIZE • Mohamed RAHOUTI •

Abderrahim FAMIRI - Abdelwahed FIDAH

Analytic solution for equation 4 is given by the following relation (Kouchade, 2004):

$$
C^{+}(t)=\frac{4}{e}\left(\sqrt{\frac{D}{\pi}} \sqrt{t}\right)
$$

Referred to gain or loss of the dimensionless mass by:

$$
\mathrm{m}^{*}(\mathrm{t})=\frac{\Delta \mathrm{m}(\mathrm{t})}{\Delta \mathrm{m}_{\max }}=\frac{\mathrm{W}(\mathrm{t})-\mathrm{W}_{\text {in }}}{\mathrm{W}_{\text {eq }}-\mathrm{W}_{\text {in }}}
$$

Where $\Delta \mathrm{m}$ and $\Delta \mathrm{m}_{\max }$ represent the variation of the sample mass (g) at time $\mathrm{t}(\mathrm{s})$ and at equilibrium; $\mathrm{W}(\mathrm{t})$ : weight at any time (g); $\mathrm{W}_{\text {in }}$ : initial weight $(\mathrm{g})$, and $\mathrm{W}_{\text {eq }}$ : weight at equilibrium (g).

The experimentally measured magnitude $\mathrm{m}^{*}(\mathrm{t})$ and the calculated analytically $\mathrm{C}^{+}(\mathrm{t})$ being dimensionless. Thus, $\mathrm{C}^{+}(\mathrm{t})$ can be written $\mathrm{C}^{+}(\mathrm{t}) \equiv \mathrm{m}^{*}(\mathrm{t})$. The slope linear part in curve (Fig. 3) represent the variation of $\mathrm{m} *(\mathrm{t})$ depending $\sqrt{\mathrm{t}}$. We can determine $\mathrm{D}$ by using the expression (5).

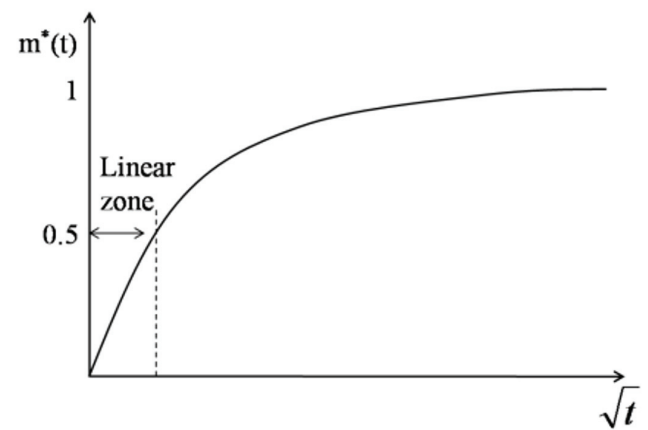

Fig. 3. Variation of $m^{*}(t)$ depending $\sqrt{t}$ for a test sample

Value of diffusion coefficient $\mathrm{D}$ is calculated by the direct method of half-rise time $t_{0,5}$ which is corresponding to $\mathrm{m}^{*}(\mathrm{t})=0.5$. In this time, the diffusion coefficient $\mathrm{D}$ is expressed by the following equation (Kouchade, 2004):

$$
\mathrm{D}=0.049 \frac{\mathrm{e}^{2}}{\mathrm{t}_{0.5}}
$$

where e: sample thickness (cm).

End splits of wood boards are determined by a parameter called splitting indicator Ie, which is given by the following relation (Hakam et al., 2005):

$$
\begin{gathered}
\mathrm{Ie}_{\max }=\frac{\mathrm{f}_{\max }}{\mathrm{L}} \cdots \cdots . . . . . \\
\mathrm{Ie}_{\text {aver }}=\frac{1}{\mathrm{~L}}\left(\frac{\sum_{1}^{\mathrm{n}} \mathrm{f}_{\mathrm{n}}}{\mathrm{n}}\right) \ldots . . \\
\Delta \mathrm{Ie}_{\mathrm{k}}=\mathrm{Ie}_{\text {after }}-\mathrm{Ie}_{\text {before }}
\end{gathered}
$$

where L: boards length $(\mathrm{cm})$; $\mathrm{n}$ : split number; $\mathrm{f}_{\mathrm{n}}$ : depth of $\mathrm{n}^{\text {th }}$ split $(\mathrm{cm})$; $\mathrm{f}_{\max }$ : depth of maximal split $(\mathrm{cm})$; Ie $_{\text {before: }}$ splitting indicator before drying; Ie $_{\text {after: }}$ splitting indicator after drying, and k: average or maximum.

\subsection{Drying tests}

Drying tests are realized in a traditional wood dryer type Cathild installed at the Forest Research Center (FRC) in Rabat. The heating in the dryer was performed by electrical resistances. The drying conditions were controlled automatically by connection to a computer with specific software, which permits visualization and control in real-time drying parameters evolution, such as relative humidity, temperature, air velocity and equilibrium moisture. The full automatic control system is used for the experiments. The dryer is filled with boards stacked as horizontal rows and separated by stickers with a section of $2 \times 2 \mathrm{~cm}^{2}$, six stickers per row (Hakam et al., 2005). Drying tests were carried out on boards with length $2.50 \mathrm{~m}$, width from 25 to $30 \mathrm{~cm}$ (according to the diameter of the log) and thickness of $3 \mathrm{~cm}$.

Drying conditions are based on drying techniques 
Table 2. Drying schedule test 1

\begin{tabular}{|c|c|c|c|c|c|c|c|c|c|}
\hline & Sequence & $\begin{array}{l}\mathrm{V} \\
(\%)\end{array}$ & $\begin{array}{c}\mathrm{Vt} \\
50 \% \mathrm{R} \\
\& 50 \% \mathrm{~L}\end{array}$ & $\begin{array}{l}\mathrm{T} \text { gradient } \\
\left({ }^{\circ} \mathrm{C} / \mathrm{h}\right)\end{array}$ & $\begin{array}{c}\mathrm{t} \\
(\mathrm{h})\end{array}$ & $\begin{array}{l}\text { MC } \\
(\%)\end{array}$ & $\begin{array}{c}\mathrm{T} \\
\left({ }^{\circ} \mathrm{C}\right)\end{array}$ & $\begin{array}{l}\text { RH } \\
\text { (\%) }\end{array}$ & $\begin{array}{c}\text { EMC } \\
(\%)\end{array}$ \\
\hline S1 & Warming 1 & 99 & 2 & 6 & & & 46 & 90 & 17.0 \\
\hline S2 & Warming 2 & 99 & 4 & & 6 & & 48 & 92 & 17.5 \\
\hline \multirow{4}{*}{ S3 } & \multirow{4}{*}{$\begin{array}{c}\text { Drying above } \\
\text { FSP }\end{array}$} & 99 & \multirow{4}{*}{9} & & & $>50$ & 48 & 87 & 16.5 \\
\hline & & 99 & & & & $50-40$ & 48 & 83 & 15.5 \\
\hline & & 90 & & & & $40-35$ & 48 & 79 & 14.2 \\
\hline & & 85 & & & & $35-30$ & 48 & 77 & 13.3 \\
\hline \multirow{7}{*}{ S4 } & \multirow{7}{*}{$\begin{array}{c}\text { Drying below } \\
\text { FSP }\end{array}$} & 75 & & & & $30-27$ & 48 & 69 & 11.5 \\
\hline & & 70 & & & & $27-24$ & 50 & 63 & 10.2 \\
\hline & & 65 & & & & $24-21$ & 52 & 60 & 9.5 \\
\hline & & 60 & 9 & & & $21-18$ & 54 & 54 & 8.1 \\
\hline & & 55 & & & & $18-15$ & 56 & 48 & 7.5 \\
\hline & & 50 & & & & $15-12$ & 58 & 45 & 6.8 \\
\hline & & 40 & & & & $12-9$ & 60 & 41 & 6.2 \\
\hline S5 & Equalizing & 40 & 4 & & 12 & 12 & 50 & 36 & 6.0 \\
\hline S6 & Conditioning & 40 & & 4 & & & 40 & & \\
\hline
\end{tabular}

Table 3. Drying schedule test 2

\begin{tabular}{|c|c|c|c|c|c|c|c|c|c|}
\hline & Sequence & $\begin{array}{l}\mathrm{V} \\
(\%)\end{array}$ & $\begin{array}{c}\mathrm{Vt} \\
50 \% \mathrm{R} \\
\& 50 \% \mathrm{~L}\end{array}$ & $\begin{array}{l}\mathrm{T} \text { gradient } \\
\left({ }^{\circ} \mathrm{C} / \mathrm{h}\right)\end{array}$ & $\begin{array}{c}\mathrm{t} \\
(\mathrm{h})\end{array}$ & $\begin{array}{l}\text { MC } \\
(\%)\end{array}$ & $\begin{array}{c}\mathrm{T} \\
\left({ }^{\circ} \mathrm{C}\right)\end{array}$ & $\begin{array}{l}\mathrm{RH} \\
(\%)\end{array}$ & $\begin{array}{c}\text { EMC } \\
(\%)\end{array}$ \\
\hline S1 & Warming 1 & 49 & 2 & 8 & & & 40 & 88 & 17.8 \\
\hline S2 & Warming 2 & 70 & 4 & & 4 & & 44 & 84 & 16.4 \\
\hline \multirow{4}{*}{ S3 } & \multirow{4}{*}{$\begin{array}{c}\text { Drying above } \\
\text { FSP }\end{array}$} & 90 & \multirow{4}{*}{9} & & & $>50$ & 48 & 82 & 15.2 \\
\hline & & 90 & & & & $50-40$ & 48 & 79 & 14.1 \\
\hline & & 90 & & & & $40-35$ & 50 & 77 & 13.2 \\
\hline & & 85 & & & & $35-30$ & 50 & 73 & 12.4 \\
\hline \multirow{7}{*}{ S4 } & \multirow{7}{*}{$\begin{array}{c}\text { Drying below } \\
\text { FSP }\end{array}$} & 80 & & & & $30-27$ & 55 & 70 & 11.0 \\
\hline & & 70 & & & & $27-24$ & 58 & 63 & 9.6 \\
\hline & & 60 & & & & $24-21$ & 60 & 55 & 8.1 \\
\hline & & 55 & 9 & & & $21-18$ & 62 & 52 & 7.4 \\
\hline & & 50 & & & & $18-15$ & 66 & 46 & 6.4 \\
\hline & & 49 & & & & $15-12$ & 68 & 39 & 5.5 \\
\hline & & 49 & & & & $12-9$ & 70 & 35 & 4.8 \\
\hline S5 & Equalizing & 49 & 4 & & 8 & 12 & 55 & 40 & 6.0 \\
\hline S6 & Conditioning & 49 & & 5 & & & 40 & & \\
\hline
\end{tabular}

where V: ventilation velocity (\%) of the maximum value, $\mathrm{Vt}$ : ventilation time (hour); $50 \%$ right \& $50 \%$ left, T: temperature $\left({ }^{\circ} \mathrm{C}\right)$, t: time of sequence (hour), RH: relative humidity (\%), EMC: equilibrium moisture content (\%), FSP: fiber saturation point, MC: wood moisture content (\%). T gradient: upwards or downwards slope of the temperature $\left({ }^{\circ} \mathrm{C} /\right.$ hour).

of hardwood and softwood species which were subject to several studies conducted by TCWFI (Technical Center for Wood and Furnishing Industries) and other authors for the eucalyptus wood species (Kantay et al., 2002, Hakam et al., 2003), which have obtained wood products with a good quality and lower deformation. 
Mahyoub AMER • Bousselham KABOUCHI - Salah El ALAMI • Brahim AZIZE • Mohamed RAHOUTI Abderrahim FAMIRI $\cdot$ Abdelwahed FIDAH

Many experiments were done on drying E. globulus wood to achieve optimum drying conditions, minimize damage and distortions (collapse, splits, cracks, etc.) and improve the wood quality. The best results of these experiments are shown in Tables 2 and 3. In the first test of drying conditions, the temperature varied from 46 to $60{ }^{\circ} \mathrm{C}$, while in the second test temperature varied between 40 and $70{ }^{\circ} \mathrm{C}$.

\section{RESULTS and DISCUSSION}

\subsection{Absorption and desorption phenomena}

\subsubsection{Absorption kinetics in the radial and tangential directions}

General profiles of water sorption kinetics in radial and tangential directions for wood samples are almost similar (Fig. 4). The obtained results of absorption kinetics in the radial and tangential directions show that the moisture of wood samples in the radial direction increased from 10 to $32.5 \%$ during 24 hours. While in the tangential direction it increased from 10 to 30.8 $\%$ in the same period. By comparing the curves of absorption kinetics in the two directions, we can deduce that the E. globulus wood is slightly more diffusive in the radial direction. In this direction, the vascular rays are the main source of the water diffusion; especially their structure, arrangement and positioning,

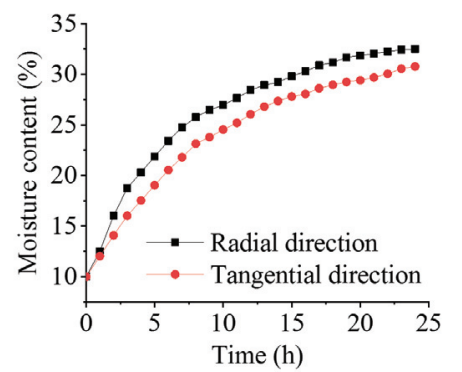

Fig. 4. Moisture absorption as a function in time for the radial and tangential directions. which promote the phenomenon of diffusivity (Kouchade, 2004). In the tangential direction, the early-wood and late-wood layers are arranged in parallel, which promotes more the diffusion in the radial direction.

\subsubsection{Desorption kinetics in the radial and tangential directions}

Fig. 5 shows that the moisture content in the two directions decreases continuously with time. In the curves of desorption, it can be seen that the moisture content decreases rapidly in the initial time. Within the first six hours, in the radial direction, the moisture decreased from 60 to $22 \%$, whereas it diminished from 60 to $27 \%$ in the tangential direction. At the end of the desorption process (24 hours), the moisture content reached almost $10 \%$ and $14 \%$ in the radial and tangential directions respectively.

In the desorption curves, we can distinguish three phases. During the first phase, the samples moisture content loss is very fast; this can be explained by the elimination of the free water through the lumens and pits of the wood structure. The second phase is characterized by a reduction of loss velocity of the moisture content; the wood samples are in the hygroscopic region (below the FSP), where the bound water and water vapor are transferred. The third phase is characterized by a very slowdown of desorption which practically becomes zero. This is mainly due to the

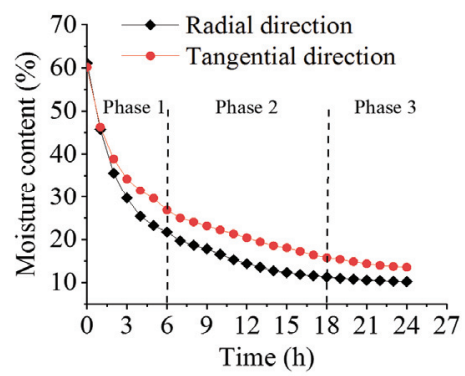

Fig. 5. Moisture desorption variation with time in radial and tangential directions. 
Table 4. Radial and tangential diffusion coefficient (D)

\begin{tabular}{lcccc}
\hline & $\begin{array}{c}\text { Radial } \\
\text { direction } \\
\mathrm{D} \times 10^{-9} \\
\left(\mathrm{~m}^{2} \mathrm{~s}^{-1}\right)\end{array}$ & $\begin{array}{c}\mathrm{CV} \\
(\%)\end{array}$ & $\begin{array}{c}\text { Tangential } \\
\text { direction } \\
\mathrm{D} \times 10^{-9} \\
\left(\mathrm{~m}^{2} \mathrm{~s}^{-1}\right)\end{array}$ & $\begin{array}{c}\mathrm{CV} \\
(\%)\end{array}$ \\
\hline \hline Absorption & 1.02 & 2.00 & 0.96 & 2.10 \\
Desorption & 2.30 & 2.20 & 1.19 & 1.70 \\
\hline
\end{tabular}

nearness of the moisture content of samples with that of the surrounding air.

\subsubsection{Diffusion coefficient}

According to the radial and tangential directions in absorption and desorption processes, the water diffusion coefficient of wood samples was calculated from equation (6). The mean values of the water diffusion coefficient in two directions in both processes and the average of their variation coefficients were reported in Table 4. The results show that the average values of the diffusion coefficient in desorption are higher than those of absorption in the two directions. We also noted that these coefficients are larger in the radial direction than in the tangential direction for both diffusion processes. These results are similar to those reported by other authors for other wood species (Siau, 1995; Khouya, 2008).

\subsection{Eucalyptus globulus wood drying}

Fig. 6 shows the drying kinetics of E. globulus wood concerning the two drying schedules described above

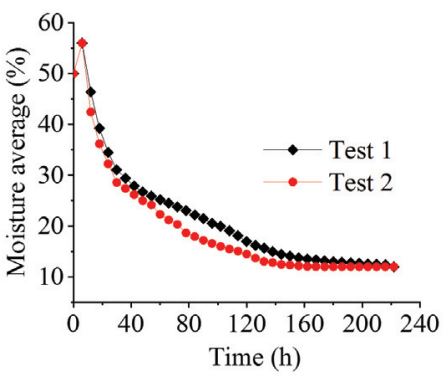

Fig. 6. Drying kinetics for E. globulus wood according to drying tables

(tests 1 and 2). It presents the evolution of the average moisture of wood as a function of time according to the conditions imposed for each test. The results obtained show that the program of drying test 1 reduce the average moisture content in wood boards from 56 to $12 \%$ during 222 h. However, the second drying test was more accelerated to reduce the wood moisture content from 56 to $12 \%$ in the drying cycle of 174 h. It should be noted that a good drying process must take into account the quality of the final product and the energy consumed. Therefore, drying E. globulus wood according to the conditions in test 1 provides the best results concerning dried wood quality.

The measurement of the boards splits before and after drying showed that the drying tests 1 and 2 reduce the deformation and degree of cracks in E. globulus wood. The value of splitting indicator $(\Delta \mathrm{Ie})$ in test 1 $(0.25 \%)$ is less than that obtained in test 2 (10.43\%).

The analysis of the values of different bows classes,

Table 5. Bows distribution before and after lumber drying

\begin{tabular}{ccccccc}
\hline \multirow{2}{*}{$\begin{array}{c}\text { Classes Bows } \\
(\mathrm{mm})\end{array}$} & Before (\%) & After (\%) & Difference (\%) & Before (\%) & After (\%) & Difference (\%) \\
\cline { 2 - 7 } & 34.32 & 42.80 & 8.48 & 40.20 & 42.60 & 2.40 \\
$3-3$ & 25.20 & 29.50 & 4.30 & 31.63 & 33.05 & 1.42 \\
$6-9$ & 16.00 & 14.45 & -2.00 & 12.50 & 13.25 & 0.70 \\
$9-12$ & 9.18 & 4.25 & -4.93 & 6.77 & 8.40 & 1.63 \\
$12-15$ & 5.80 & 5.50 & -0.30 & 2.50 & 2.35 & -0.15 \\
$>15$ & 9.50 & 3.50 & -6.00 & 4.00 & 5.14 & 1.14 \\
\hline
\end{tabular}


Mahyoub AMER • Bousselham KABOUCHI - Salah El ALAMI • Brahim AZIZE • Mohamed RAHOUTI Abderrahim FAMIRI $\cdot$ Abdelwahed FIDAH

before and after drying, is reported in Table 5. This table indicates that the drying tests affect bows values. The more important variations are observed for test 1 .

\section{CONCLUSION}

We have investigated the absorption and desorption kinetics of water in the E. globulus wood in the radial and tangential directions. We also have determined the diffusion coefficients for this wood. The results show that E. globulus wood has a slightly higher diffusivity in the radial direction than in the tangential direction. The average values of the diffusion coefficient in the radial direction are larger than that of the tangential direction in both of absorption and desorption process. Drying tests done on E. globulus wood shows that the appropriate drying conditions for this wood correspond to the drying schedule 1 (Table 2). This later also reduce the deformations during the drying process.

\section{REFERENCES}

Amer, M., Kabouchi, B., Rahouti, M., Famiri, A., Fidah, A. 2017. Determination of growth stresses indicator, moisture profiles and basic density of clonal eucalyptus wood. Journal of the Indian Academy Wood Science 14(1): 91-98.

Baronas, R., Ivanauskas, F., Juodeikien, L., Kajalavičius, A. 2001. Modelling of moisture movement in wood during outdoor storage. Nonlinear Analysis: Modelling and Control 6(2): 3-14.

Batista, D.C., Klitzke, R.J., Da Rocha, M.P., Bolzon de Muñiz, G.I., Batista, T.R. 2013. Volume loss as a tool to assess kiln drying of Eucalyptus Wood. Floresta e Ambiente 20(2): 250-256

Bennani, L., Elkouali, M., Talbi, M., Ainane, T. 2017. Modelling the absorption process of water in wood in the transient regime. International Journal of Chemical Science 15(2): 137-147.
Chang, Y.S., Shin, H.K., Kim, S., Han, Y., Kim, M.J., Eom, C.D., Lee, Y.G., Shim, K.B. 2017. Evaluation of drying properties and yields of domestic Quercus species for enhancing utilization. Journal of the Korean Wood Science and Technology 45(5): 622-628.

Engelund, E.T., Thygesen, L.G., Svensson, S., Hill, C.A.S. 2013. A critical discussion of the physics of wood-water interactions. Wood Science and Technology 47: 141-161.

Famiri, A., Kabouchi, B., Hakam, A., Gril, J. 2001. Sawing and growth stresses in green wood of Eucalyptus grandis \& E. gomphocephala. Forest Science, Bulgaria, 1/2: 45-50.

Franke, B., Franke, S., Schiere, M., Müller, A. 2016. Moisture diffusion in wood-Experimental and numerical investigations. Vienna-Austria. WCTE World Conference on Timber Engineering. 22-25 August (2016), pp. 1-8.

Ghazil, A. 2010. Etude de la migration des fluides dans le bois. PhD. Thesis, Université Henri Poincaré, Nancy 1, France.

Hakam, A., Dikrallah, A., Kabouchi, B., Famiri, A., Walia-Allah, M., El Abid, A. 2005. Eucalyptus wood drying. Journal of Physics IV France 123: 327-330.

Hakam, A., Dikrallah, A., Walia-Allah, M., Famiri, A., Kabouchi, B., El Abid, A., Fechtal, M. 2003. Contrôle et quantification de la dégradation mécanique du bois pendant le séchage. Cas d'eucalyptus. Physical Chemistry News 13: 110 $-114$.

Houngan, C.A., Awanto, C., Houndedako, S., Anjorin, M., Vianou, A. 2015. Mass diffusivity determination of Teak wood (Tectona grandis) used as building material. Int. Conference on Computational Heat and Mass Transfer, Procedia Engineering 127: 201-207.

Jannot, Y., Kanmogne, A., Talla, A., Monkam, L. 2006. 
Experimental determination and modelling of water desorption isotherms of tropical woods: afzelia, ebony, iroko, moabi and obeche. Holz als Roh. und Werkstoff, 64: 121-124.

Kang, C.W., Kang, H.Y. 2018. Development of a Kiln dry schedule for Lindera erythrocarpa grown in Hongsung, Chungnam Province, Korea. Journal of the Korean Wood Science Technology 46(1): 10-16.

Kantay, R., Unsal, O., Korkut, S. 2002. Drying problems of fast growing tree species: Evaluation of Maritime pine (Pinus pinaster Ait) and Eucalyptus (Eucalyptus camaldulensis Dehn) wood. Izmit-Turkey, Conference, Meeting Management of Fast Growing Plantations (IUFRO 2002), pp 208-212.

Khouya, A. 2008. Contribution aux études expérimentale et numérique d'un processus de séchage du bois. PhD. Thesis, Université Abdelmalek Essaadi, Tétouan, Morocco.

Kim, H., Han, Y., Park, Y., Yang, S.Y., Chung, H., Eom, C.D., Lee, H.M., Yeo, H. 2017. Finite difference evaluation of moisture profile in Boxedheart large-cross-section Square timber of Pinus densiflora during high temperature drying. Journal of the Korean Wood Science and Technology 45(6): 762-771.

Kouchadé, A.C. 2004. Détermination en routine de la diffusivité massique dans le bois par méthode inverse à partir de la mesure électrique en régime transitoire. PhD. Thesis, Ecole Nationale du génie Rural des Eaux et des Forets, Nancy, France.

Lee, J.M., Lee, W.H. 2018. Dimensional stabilization through heat treatment of thermally compressed wood of Korean Pine. Journal of the Korean Wood Science and Technology 46(5): 471-485.

Maziri, A., El Ghorba, M., Chergui, M., Famiri, A., Ziani, M., Kabouchi, B. 2010. Etude des contraintes de croissance chez l'Eucalyptus camaldulensis et leur relation avec les fentes d'abattage. Physical
Chemistry News 53: 15-21.

Noorolahi, S., Khazaei, J., Jafari, S. 2008. Modeling Cyclic water absorption and desorption characteristics of three varieties of wood. Tokyo, Japan, World conference on agricultural information and IT. 24-27 August (2008), pp 13-22.

Okoh, E.T. 2014. Water absorption properties of some tropical timber species. Journal of Energy and Natural Resources 3(2): 20-24.

Pang S.J., Jeong G.Y. 2019. Effects of density, temperature, size, grain angle of wood materials on nondestructive moisture meters. Journal of the Korean Wood Science and Technology 47(1): 40-50.

Peralta, P.N., Bangi, A.P. 2003. A nonlinear regression technique for calculating the average diffusion coefficient of wood during drying. Wood and Fiber Science 35(3): 401-408.

Sandoval-Torres, S., Hernández-Bautista, E., RodríguezRamírez, J., Carrillo Parrab, A. 2014. Numerical simulation of warm-air drying of Mexican softwood (Pinus pseudostrobus): An empirical and mechanistic approach. Chemical and Biochemical Engineering Quartely 28: 125-133.

Shi, S.Q. 2007. Diffusion model based on Fick's second law for the moisture absorption process in wood fiber-based composites: is it suitable or not. Wood Science and Technology 41(8): 645-658.

Siau, J. 1995. Wood influence of water on physical properties. PhD. Thesis, Virginia Polytechnic Institute and State University.

Sonderegger, W., Vecellio, M., Zwicker, P., Niemz, P. 2011. Combined bound water and water vapour diffusion of Norway spruce and European beech in and between the principal anatomical directions. Holzforschung 65: 819-828.

Tamme, V., Muiste, P., Mitt, R., Tamme, H. 2011. Determination of effective diffusion coefficient and mechanical stress of pine wood during convective 
Mahyoub AMER • Bousselham KABOUCHI - Salah El ALAMI • Brahim AZIZE • Mohamed RAHOUTI • Abderrahim FAMIRI $\cdot$ Abdelwahed FIDAH

drying. Baltic Forestry 17: 110-117.

Travan, L., Allegretti, O., Negri, M. 2010. Eucalyptus drying process: qualitative comparison of different clones cultivated in Italy. Edinburgh, UK. The Final Conference of COST Action E53. 4-7 May (2010), pp. 57-70.

Vasic, M., Radojevic, Z., Grbavcic, Ž. 2012. Calculation of the effective diffusion coefficient during the drying of clay samples. Journal of the Serbian
Chemical Society 77(4): 523-533.

Wessels, C.B., Crafford, P.L., Toit, B. Du., Grahn, T., Johansson, M., Lundqvist, S.O., Sall, H., Seifert, T. 2016. Variation in physical and mechanical properties from three drought tolerant Eucalyptus species grown on the dry West coast of Southern Africa. European Journal of Wood and Wood Products 74: 563-575. 